\title{
Performance-based plastic design of a high rise moment resisting frame with friction dampers
}

\author{
C. S. Patil ${ }^{1}$, V. B. Patil ${ }^{1}$ \& S. B. Kharmale ${ }^{2}$ \\ ${ }^{1}$ B. V. B. College of Engineering and Technology, India \\ ${ }^{2}$ Government College of Engineering and Research, India
}

\begin{abstract}
A performance-based plastic design (PBPD) method for a steel moment resisting frame (MRF) considering a pre-selected yield mechanism and uniform target drift has been recently proposed. This method when adopted to design high rise MRF for relatively high target drift exhibits maximum residual inter-storey drift demands in excess of target plastic drift, which is perceptible for a building's occupants and could cause human discomfort. The use of an energy dissipation device such as a friction damper for establishing global drift limits compatible with the same rate of peak inter-storey drift limits is proposed for PBPD of high rise MRF. The PBPD design case study of a 21-storey MRF with the use of friction dampers in order to achieve a uniform target drift compatible with peak interstorey drift limits is presented in this paper. The analytical validation of this design through nonlinear static pushover analysis (NSPA) and nonlinear time history analysis (NTHA) under selected strong motion records justified the use of friction dampers to achieve performance objective in terms of uniform target drift.

Keywords: performance-based plastic design (PBPD), inter-storey drift, friction dampers, nonlinear static pushover analysis (NSPA), nonlinear time history analysis (NTHA).
\end{abstract}

\section{Introduction}

In the performance based plastic design (PBPD) method, the equivalent seismic forces have specific values for different structural system irrespective of their ductility demand, even when it became clear that many structures had survived earthquakes capable of inducing inertia forces many times larger than those corresponding to their structural strength, if a linear response was assumed. The 
main advantages of a displacement based design is the adoption of displacement as the main parameter (performance index) from the very beginning of the problem, which enables the designer to better control the seismic damage (Bazeos [1]). Performance-based design is a more general design philosophy in which the design criteria are expressed in terms of achieving stated performance objectives when the structure is subjected to stated levels of seismic hazard. The performance targets may be a level of stress not to be exceeded, a load, a displacement, a limit state or a target damage state (Ghobarah [2]). Displacement is directly related to damage, hence displacement based approaches are preferred to force-based ones. This is achieved by utilizing a simple relation that correlates a damage index, such as the inter-storey drift ratio (IDR), with the maximum floor displacements of the building (Karavasilis et al. [3]). The main disadvantage of the method is a representation of structure by an equivalent SDOF system, which is associated with a loss of modelling accuracy. A displacement-based approach of PBSD of various lateral load resisting systems using target inelastic drift and pre-selected yield mechanism were recently developed in the University of Michigan by Lee and Goel [4].

\section{Performance-based plastic design of steel moment frames}

Diverse seismic design methods have been suggested to estimate more rational design base shear demand and obtain adequate capacities in terms of strength, ductility, and energy dissipation for structures in the severe seismic zones. The use of the principle of energy conservation in seismic design has also been a part of those methods. In a previous study by Leelataviwat et al. [5], a new performancebased plastic design procedure using the concept of energy balance applied to a preselected yield mechanism with adequate strength and ductility was developed. The required design base shear was derived corresponding to a target maximum drift for the selected yield mechanism by using the input energy for the design pseudo-velocity spectrum. Design base shear calculated by the modified energy balance equation can be a good approach to solve above problems.

$$
\mathrm{E}_{\mathrm{e}}+\mathrm{E}_{\mathrm{p}}=\frac{1}{2} \gamma \mathrm{M}\left(\frac{1}{2} \mathrm{M} \mathrm{S}_{\mathrm{v}}{ }^{2}\right)^{2}=\frac{1}{2} \mathrm{M} \gamma\left(\frac{\mathrm{T}_{1}}{2 \pi} \frac{\mathrm{S}_{\mathrm{a}}}{\mathrm{g}} \mathrm{g}\right)^{2}
$$

where $E_{e}$ and $E_{p}$ are the elastic and plastic components of work done during pushing the structure monotonically up to the target maximum drift and $\gamma$ is the modification factor calculate as;

$$
\gamma=\frac{2 \mu_{s}-1}{R_{\mu}^{2}}
$$

where, $R_{\mu}$ is the ductility reduction factor and $\mu_{s}$ is structural ductility factor or target displacement ductility ratio. The admissible solution of eq. (1) gives the required design base shear coefficient as given in eq. (3).

$$
\frac{V_{\text {by }}}{W}=\frac{-\alpha+\sqrt{\alpha^{2}+4 \gamma\left(s_{a} / g\right)^{2}}}{2}
$$


where $\alpha$ is a dimensionless parameter, which depends on the stiffness of the structure, the modal properties, and the intended drift level, and is given by

$$
\alpha=\left(\sum_{\mathrm{i}=1}^{\mathrm{n}}\left(\beta_{\mathrm{i}}-\beta_{\mathrm{i}+1}\right) \mathrm{h}_{\mathrm{i}}\right) \quad\left(\frac{\mathrm{w}_{\mathrm{n}} \mathrm{h}_{\mathrm{n}}}{\sum_{\mathrm{i}=1}^{\mathrm{n}} \mathrm{W}_{\mathrm{i}} \mathrm{h}_{\mathrm{i}}}\right) \frac{\theta_{\mathrm{p}} 8 \pi^{2}}{\mathrm{~T}^{2} \mathrm{~g}}
$$

where, $\frac{S_{a}}{g}$ is normalized design pseudo-acceleration, $\gamma$ is energy modification factor, $T$ is fundamental time period, $h_{i}$ is the height of $\mathrm{i}^{\text {th }}$ floor measured from ground, and $\theta_{p}$ is the plastic drift. For the design of steel MRF with specific target drift (or target displacement ductility ratio) $\theta_{p}$ can be evaluated by assuming suitable value of yield drift, $\theta_{y}$ (in range of $1.0 \%$ to $1.1 \%$ ). Shear proportioning factor $\beta_{i}=\left(\frac{V_{i}}{V_{n}}\right)$ where $V_{i}$ and $V_{n}$, respectively, are the static storey shears at level $i$ and at the top level as computed from the linear lateral force distribution shape of the first mode of vibration. $W_{i}$ and $W_{j}$ are the weight of the structure at level $i$ and $j$, respectively, hi and $\mathrm{h}_{\mathrm{j}}$ are the heights of beam level $i$ and $j$ from the ground, respectively and $V_{b y}$ is the design base shear.

\section{Analytical model of twenty one-storey steel MRF}

A steel moment resisting frame of 5 bays@5.0 m and 21 stories each@4.0 m frame is to be designed for a maximum target displacement ductility ratio of 4 . Damping ratio is to be 5\%, Medium soil strata. A36 steel confirmed with AISC (US Standard). Substituting these terms into eq. (2), the modification factor, $\gamma$ for energy balance equation can be determined as: 0.438 . Alternatively, the design pseudo-velocity value can be calculated by using an estimated fundamental period, $T$ for steel moment frames provided by the IS 1893:2002 is $2.36 \mathrm{sec}$. The average response acceleration coefficient is 0.581 for medium soil sites as per IS 1893:2002 [6]. Design base shear is calculated as per eqs (1), (3) and (4) for 0.06 value of yield drift is $3289.57 \mathrm{kN}$. The modelling and nonlinear dynamic timehistory analyses of the building frames were carried out using SAP2000. For all analyses the geometric nonlinearity and the nominal lateral stiffness from gravity frames are neglected.

\subsection{Friction devices}

Friction devices do not change the inherent properties of the structure, their cost is relatively low, and their installation and maintenance are simple [7-9]. Pall et al. [9] and Pall and Pall [10] developed passive friction dampers based upon the automotive brake which are simple in construction. Basically, these consist of series of steel plates, which are specially treated to develop very reliable friction. These plates are clamped together and allowed to slip at a predetermined load (fig. 1). Decades of research and testing have led to perfecting the art of friction. Their performance is reliable, repeatable and they possess large rectangular hysteresis loops with negligible fade. Pall friction dampers are passive energy 
dissipation devices and, therefore, need no energy source other than earthquakes to operate it.

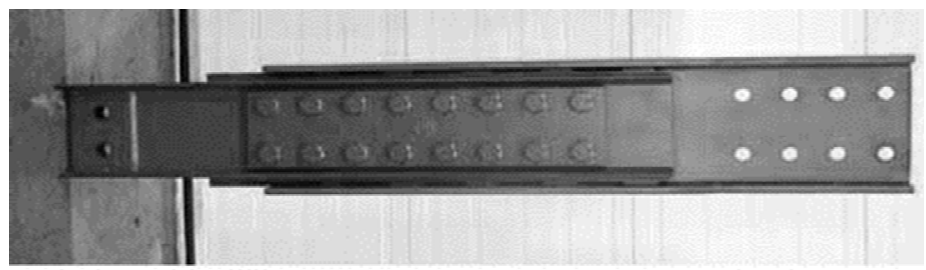

Figure 1: Pall single diagonal tension/compression brace with friction damper.

\subsection{Analytical modelling of the friction damped braces (FDBs)}

As mentioned before, the friction damped braces (FDBs) that are modeled in all frames are Pall single diagonal tension/compression braces with a friction device at one end. The friction damped braces were modeled using link elements assigned with an appropriate plasticity model. Based upon the behavior obtained by Pall and Pall [10], the characterization of their brake lining frictional system in terms of an elastic-perfectly plastic model is appropriate. As suggested by Dr. Avtar Pall [9], president of Pall Dynamics Ltd, in personal communication, the values of the Wen plasticity property parameters that were assigned to the model of the friction damped braces are $K_{e}=$ Effective Stiffness $=A E / L$ (properties of brace), $F_{y}=$ slip load of the friction device, post-yield stiffness ratio $r=0.0001$ and yielding exponent $=10$. In this study we have provided the FDBs from bottom to tenthfloor and bottom to top -floor for seismic analysis as shown in fig. 2.
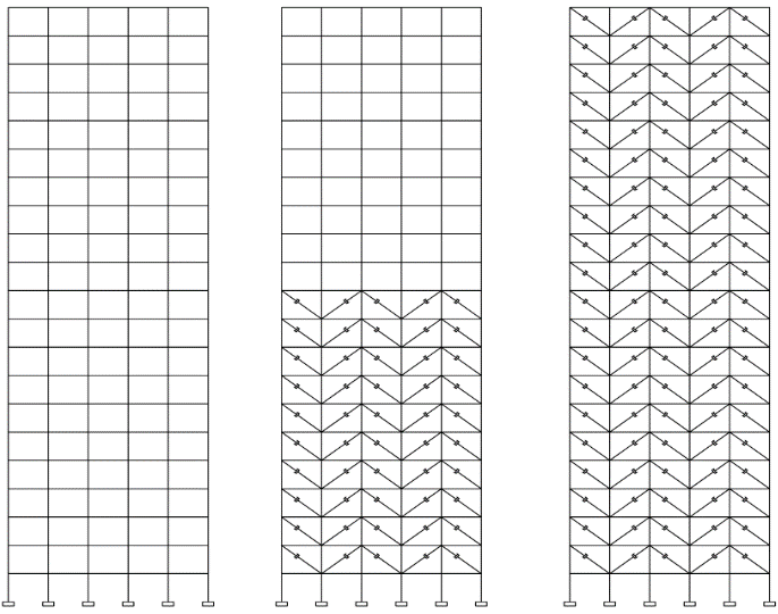

Figure 2: Multi-storey braced friction damper frame 2D view. 


\subsection{Nonlinear Static Pushover Analysis (NSPA)}

Nonlinear static pushover analysis is used to evaluate the expected performance of a structural system by estimating its strength, deformation demands in design earthquakes and failure pattern. This evaluation is based on an assessment of important performance parameters, including global drift and inelastic element deformations. The model of design is subjected to the unidirectional monotonic push till the respective target displacement so as to induce significant inelastic deformations in the system. The capacity curve roof displacement versus base shear plot and the approximate one and yield point (yield displacement, $D_{y}$; yield base shear, $V_{b y}$ ) is obtained for each design. For each design, yield drift, $\theta_{y}$ $\left(D_{y} / H\right)$ and yielding hierarchy is obtained from NSPA. This $\theta_{y}$ is later used for the calculation of achieved displacement ductility ratio, $\mu_{s}$

\subsection{Nonlinear Time History Analysis (NTHA)}

The method consists of performing a time-history analysis in the non-linear domain. The seismic action is directly applied, by means of accelerograms, at the base of the structure. In order to investigate the performance of MRF in high to medium seismicity, Nonlinear Time History Analysis is performed under the ground motion records of the 1940 El Centro, 1995 Northridge and 1955 Kobe earthquakes. Details of these ground motion records are shown in table 1 and fig. 3.

Table 1: Details of ground motion record for NTHA.

\begin{tabular}{|l|l|c|c|}
\hline Earthquake & Station & PGA & Scale factor \\
\hline 1940 El Centro & Imperial Valley & $0.2584 \mathrm{~g}$ & 1.65 \\
\hline 1995 Northridge & Sepulveda VA & $0.8026 \mathrm{~g}$ & 1.57 \\
\hline 1955 Kobe earthquake & Kobe, KJM & $0.7105 \mathrm{~g}$ & 1.02 \\
\hline
\end{tabular}

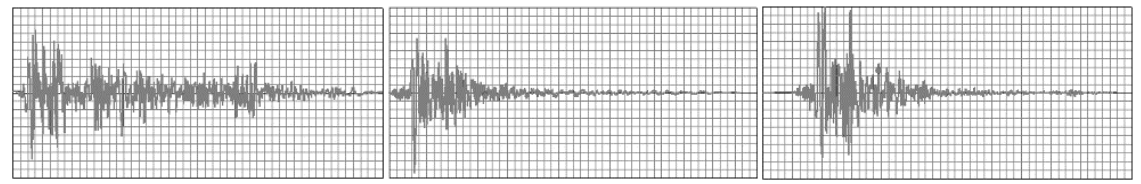

(a)

(b)

(c)

Figure 3: Acceleration time history of ground motions for NTHA (a) $1940 \mathrm{El}$ Centro earthquake; (b) 1995 Northridge earthquake; (c) 1955 Kobe earthquake.

\section{Results and discussion}

This section presents results obtained from Nonlinear Time History Analysis and Nonlinear static pushover analysis. As discussed before, the roof displacement versus base shear plot obtained from NSPA of PBPD design is $(0.525 \mathrm{~m}$, 
$7746.4 \mathrm{kN}$ ). For PBPD design, initial assumption of yield drift, $\theta_{y}$ is required in the range of $0.5 \%$ to $1.0 \%$ and the yield drift obtained $\left(\theta_{y}=0.63 \%\right)$ from NSPA is near to its initial assumption which indicates the PBPD model exhibit exactly same lateral load resisting behavior as assumed in design formulation.

The NSPA result show that target displacement ductility ratio $\mu_{s}=3.95$ is achieved using Performance Based Plastic Design method. Analytical validation of this design showed that PBPD method is very effective in achieving performance objectives in terms of target displacement ductility and pre-selected yield mechanism (as shown in fig. 4).

Fig. 4 provides pushover plot along with yielding hierarchy as obtained respective NSPA. From these yielding hierarchies, it can be observed that PBPD design exhibit more gradual and sequential yield pattern and also proves that the pre-selected yield mechanism as assumed in PBPD design is almost achieved and hence one of the performance criteria is satisfied for the case of PBPD. The ultimate roof displacement, $D_{m}$ obtained from NTHA of each design under specific ground motion record is used to obtain the achieved displacement ductility, $\mu_{a}$ as ratio of $D_{m}$ to $D_{y}$ be shown in table 2 .

Table 2: Details of ground motion record for NTHA.

\begin{tabular}{|l|c|c|c|c|}
\hline \multirow{2}{*}{ Earthquake } & $\mu_{s}$ & \multicolumn{3}{|c|}{$\mu_{a}$} \\
\cline { 3 - 5 } & & Bare frame & $\begin{array}{c}\text { Half } \\
\text { damped }\end{array}$ & $\begin{array}{c}\text { Damped } \\
\text { frame }\end{array}$ \\
\hline 1940 El Centro & 4.00 & 2.08 & 2.49 & 2.00 \\
\hline 1995 Northridge & 4.00 & 2.09 & 2.50 & 2.09 \\
\hline 1955 Kobe earthquake & 4.00 & 2.17 & 1.61 & 1.42 \\
\hline
\end{tabular}

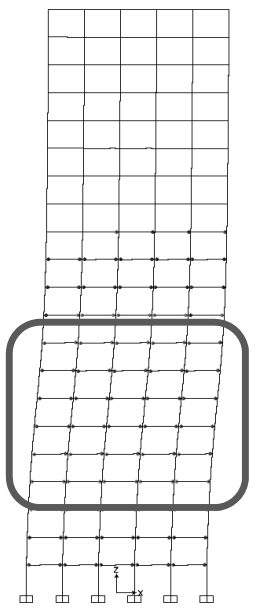

(a)

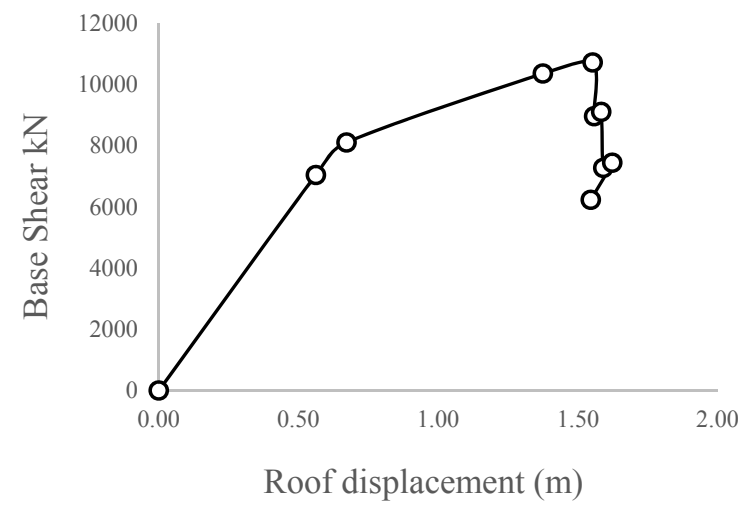

(b)

Figure 4: (a) Yield mechanism; (b) Capacity curve 21 - storey steel MRF. 
One of main objective of using FDBs to improve structure lateral response is satisfied by reviewing diagram of the roof storey lateral response history of each floor are shown in fig. 5. Considering the presented diagrams in figure 6, from qualitative point of view, this point could be inferred that using FDBs in all reviewed situations causes a significant decrease in the roof storey response history affected by earthquakes. From the quantitative point of view the use of FDBs in all floor buildings leads to $48 \%$ decrease of the maximum displacement affected by earthquake (as shown in fig. 6).

According to fig. 7, from the use of FDBs in all situations leads to complying floor drift. But with increasing the number of floors, the amount of controlled drift by structure with FDBs, gets uniform and comfortable to the structure without damper. From the quantitative point of view and according figures, the maximum amount of drift index decrease relates to the $18^{\text {th }}$ floor that estimated to be $85 \%$.

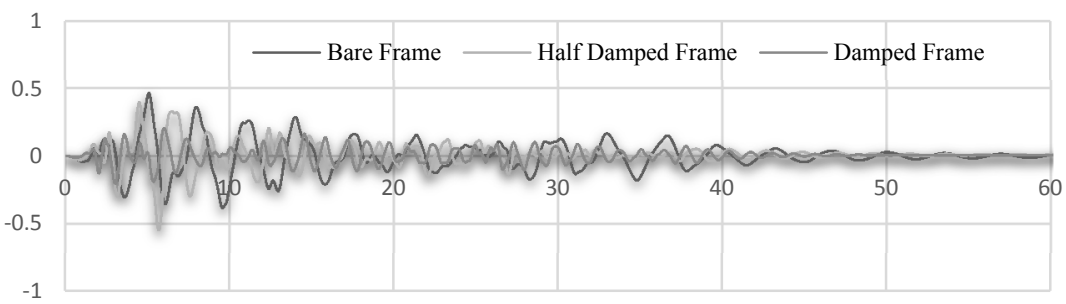

(a)

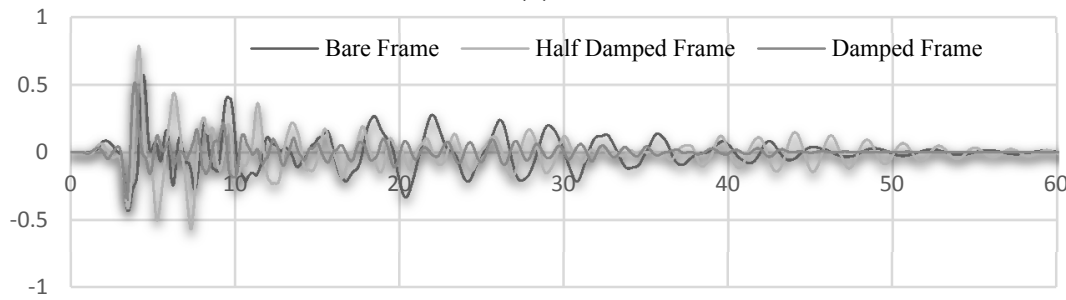

(b)

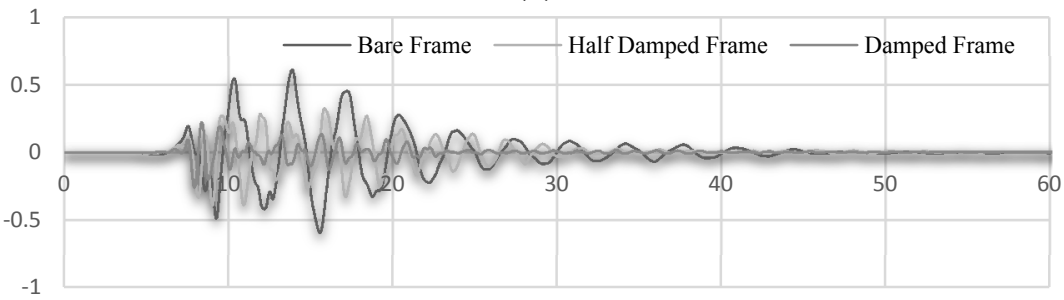

(c)

Figure 5: Roof storey displacement history affected by (a) 1940 El Centro earthquake; (b) 1995 Northridge earthquake; (c) 1955 Kobe earthquake. 


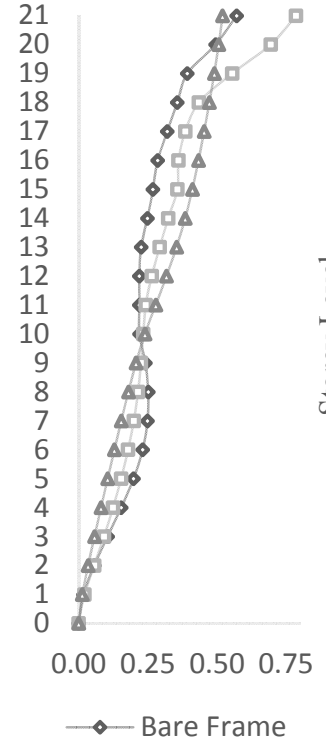

(a)

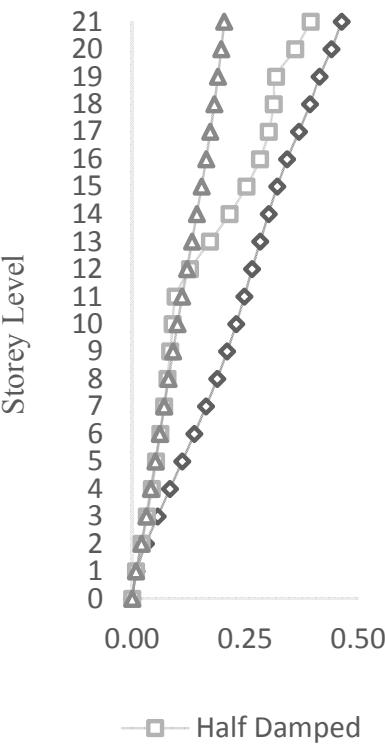

(b)

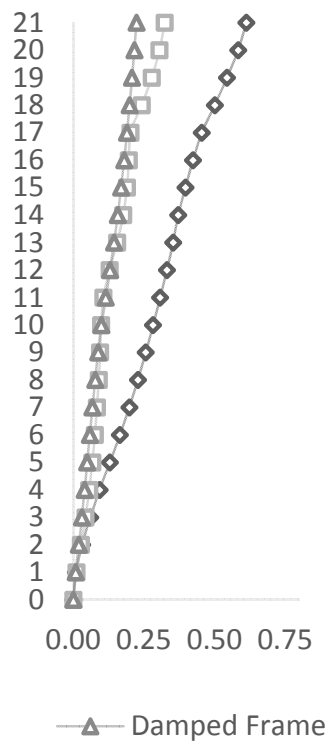

(c)

Figure 6: Displacement of steel MRF from NTHA for (a) 1940 El Centro earthquake; (b) 1995 Northridge earthquake; (c) 1955 Kobe earthquake.

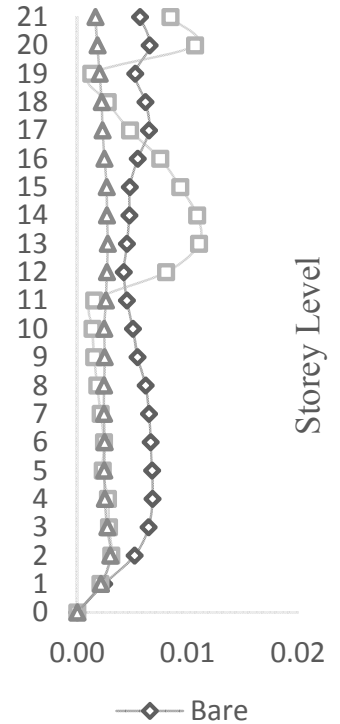

(b)

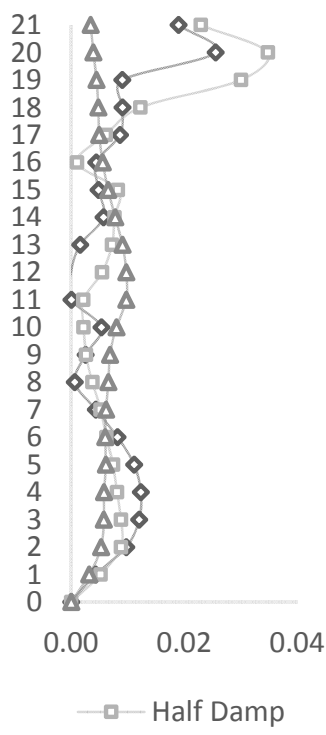

(b)

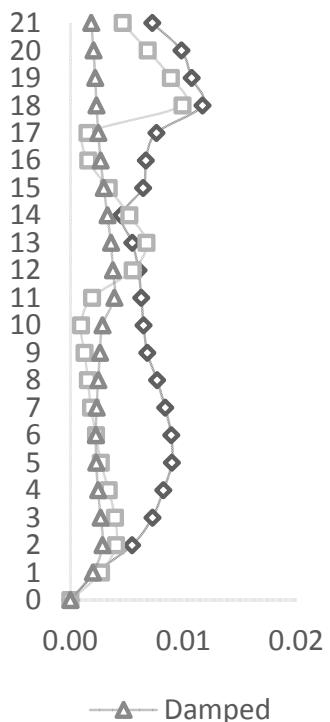

(c)

Figure 7: Inter-storey drift ratio for (a) 1940 El Centro earthquake; (b) 1995 Northridge earthquake; (c) 1955 Kobe earthquake. 


\section{Conclusion}

The objective of work presented in this paper is to compare the seismic performance of steel MRF designed with displacement-based approach and the behaviour of friction damped braced frames. For this purpose 21 -storey steel MRF is designed by PBPD method developed by Lee and Goel [4]. The seismic performance of these designs with pall friction braced damper is evaluated through NSPA and NTHA. The concluding remarks on the seismic performance of these designs are summarized as follows:-

1. The displacement-based approach include actual inelastic target drift and an energy-based formulation in the design procedure thus, it is found to be very effective in achieving a certain inelastic displacement for a given earthquake scenario.

2. Analytical validation of this design showed that PBPD method is very effective in achieving performance objectives in terms of target displacement ductility and pre-selected yield mechanism.

3. Simulation results indicate that structural inter-storey drift of structure is exceed at top storey of structure with varying percentage. Results of the analyses that were carried out showed average reductions in the peak interstorey drift ratios of almost $85 \%$.

4. As a strategy, considering good performance of FDBFs in the relative and absolute displacement decrease of floors, it is expected that the use of friction decreases the flexural moment at columns significantly.

\section{References}

[1] N. Bazeos, "Comparison of three seismic design methods for plane steel frames." Soil Dynamics and Earthquake Engineering, 29, pp. 553-562, 2009.

[2] Ahmed Ghobarah, "Performance-based design in earthquake engineering: state of development." Engineering Structures, 23, pp. 878-884, 2001.

[3] T.L. Karavasilis, N. Bazeos, D.E. Beskos, "Maximum displacement profiles for the performance based seismic design of plane steel moment resisting frames." Engineering Structures, 28, pp. 9-22, 2006.

[4] Lee Soon-Sik and Goel, S. C. "Performance-Based Design of Steel Moment Frames Using Target Drift and Yield Mechanism” Report No. UMCEE 0117, Department of Civil \& Environment Engineering, University of Michigan, Ann Arbor, MI, USA, 2001.

[5] Leelataviwat, S., Goel, S. C. and Stojadinovic, B., "Toward Performance Based Seismic Design of Structures." Earthquake Spectra, EERI, 15, pp. 435-461, 1999.

[6] IS 1893 (Part 1): 2002, Criteria for Earthquake Resistant Design of Structures, Part 1: General Provisions and Buildings. Bureau of Indian Standards, New Delhi 110002. 
82 Earthquake Resistant Engineering Structures X

[7] Anil K. Chopra and Rakesh K. Goel, "Evaluation of NSP to Estimate Seismic Deformation: SDF Systems." Journal of Structural Engineering, 126, pp. 482-490, 2000.

[8] Imad H. Mualla and Borislav Belev. "Performance of steel frames with a new friction damper device under earthquake excitation." Engineering Structures, 24, pp. 365-371, 2002.

[9] Pall, A., Marsh, C., and Fazio, P., "Friction joints for seismic control of large panel structures.” Journal of Prestressed Concrete Institute, 25(6), pp. 38-61, 1980.

[10] Pall, A. and Pall R. T., "Performance-based design using Pall friction dampers - An economical design solution." Proc. of the $13^{\text {th }}$ World Conference on Earthquake Engineering, Vancouver, B. C., Canada, 2004. 